\title{
Socio-economic factors associated with delivery assisted by traditional birth attendants in Iraq, 2000 Seter Siziya ${ }^{1}$, Adamson S Muula*2 and Emmanuel Rudatsikira ${ }^{3}$
}

\author{
Address: ${ }^{1}$ Department of Community Medicine, University of Zambia, School of Medicine, Lusaka, Zambia, ${ }^{2}$ Division of Community Health, \\ University of Malawi, College of Medicine, Blantyre, Malawi and ${ }^{3}$ Division of Epidemiology and Biostatistics, Graduate School of Public Health, \\ San Diego State University, San Diego, California, USA \\ Email: Seter Siziya - ssiziya@yahoo.com; Adamson S Muula* - muula@email.unc.edu; Emmanuel Rudatsikira - erudatsikira@llu.edu \\ * Corresponding author
}

Published: 2 April 2009

BMC International Health and Human Rights 2009, 9:7 doi:10.1 186/1472-698X-9-7
Received: 28 August 2008

Accepted: 2 April 2009

This article is available from: http://www.biomedcentral.com/1472-698X/9/7

(C) 2009 Siziya et al; licensee BioMed Central Ltd.

This is an Open Access article distributed under the terms of the Creative Commons Attribution License (http://creativecommons.org/licenses/by/2.0), which permits unrestricted use, distribution, and reproduction in any medium, provided the original work is properly cited.

\begin{abstract}
Background: Traditional birth attendants (TBAs) are likely to deliver lower quality maternity care compared to professional health workers. It is important to characterize women who are assisted by TBAs in order to design interventions specific to such groups. We thus conducted a study to assess if socio-economic status and demographic factors are associated with having childbirth supervised by traditional birth attendants in Iraq.
\end{abstract}

Methods: Iraqi Multiple Indicator Cluster Survey (MICS) data for 2000 were used. We estimated frequencies and proportions of having been delivered by a traditional birth attendant and other social characteristics. Logistic regression analysis was used to assess the association between having been delivered by a TBA and wealth, area of residence (urban versus rural), parity, maternal education and age.

Results: Altogether 22,980 women participated in the survey, and of these women, 2873 had delivery information and whether they were assisted by traditional birth attendants (TBAs) or not during delivery. About I in 5 women (26.9\%) had been assisted by TBAs. Compared to women of age 35 years or more, women of age $25-34$ years were $22 \%$ (AOR $=1.22,95 \% \mathrm{Cl}[1.08,1.39]$ ) more likely to be assisted by TBAs during delivery. Women who had no formal education were $42 \%$ $(A O R=1.42,95 \% \mathrm{Cl}[1.22,1.65])$ more likely to be delivered by TBAs compared to those who had attained secondary or higher level of education. Women in the poorest wealth quintile were 2.52 $(A O R=2.52,95 \% \mathrm{Cl}[2.14,2.98])$ more likely to be delivered by TBAs compared to those in the richest quintile. Compared to women who had 7 or more children, those who had I or 2 were $28 \%(\mathrm{AOR}=0.72,95 \% \mathrm{Cl}[0.59,0.87])$ less likely to be delivered by TBAs.

Conclusion: Findings from this study indicate that having delivery supervised by traditional birth attendants was associated with young maternal age, low education, and being poor. Meanwhile women having I or 2 children were less likely to be delivered by TBAs. These factors should be considered in the design of interventions to reduce the rate of deliveries assisted by TBAs in favour of professional midwives, and consequently reduce maternal and neonatal mortality rates and other adverse events. 


\section{Background}

Maternal and neonatal morbidity and mortality arising from inadequate health services is an important global health concern. Mortality rates are often higher in lowand mid-income countries where investment in human resources and medical resources are limited [1]. In the past decade, the importance of maternal health has been rekindled following its expected inclusion within the Millennium Development Goals (MDGs); eight in total, the fifth of which is on the reduction of maternal mortality $[2,3]$. Rasch has argued that skilled birth attendants are a necessity for the reduction of maternal mortality [1].

Darmstadt et al [4] have reported a study in Egypt that while most mothers usually received antenatal care from physicians, traditional birth attendants (TBAs) conducted most deliveries. Anwar et al [5] have reported that lowincome families were less likely to have skilled birth attendants at birth, thus raising an equity issue. Using data from Bangladesh, Fonczak et al [6] reported that TBAs with more experience were more likely to use potentiallyharmful birthing practices which increased the risk of postpartum morbidity among women with births at home.

Of all causes of maternal deaths in 1999 in Iraq, 46.4\% of them were due to bleeding [7]. While the literature is certainly not short of articles that demonstrate the adverse effects of being supervised in delivery by traditional attendants, in many settings of the world however, many women continue to be supervised by this group of health care providers. Women may choose to be delivered by TBAs because of culturally appropriate and respectful care that traditional birth attendants provide [8]. Women may also have TBAs for assistance during delivery because that may be the only option when health facilities and professional trained staff may be less available. In 2002, in Iraq, there were only 7.0 physicians/10,000 population and 8.8 nurses $/ 10,000$ population. It is estimated that $50 \%$ of all births are home delivered, and TBAs attend $18 \%$ of the total deliveries. Neonatal mortality rate/1000 live births and maternal mortality ratio/100000 live births for Iraq have been estimated to be 67.0 and 294, respectively [7].

Using data from the 2000 Multiple Indicator Cluster Survey (MICS) of Iraq, we aimed to assess factors associated with having a delivery supervised by a TBA within the past 12 months. The MICS is coordinated by UNICEF and has as its primary objectives the following: to provide up-todate information for assessing the situation of children and women at the end of the decade and for looking forward to the next decade; "to furnish data needed for monitoring progress toward goals established in 1990 at the World Summit for Children and as a basis for future action and; to contribute to the improvement of data and monitoring systems a country and to strengthen technical expertise in the design, implementation, and analysis of such systems" [9].

\section{Methods \\ Survey design}

A description of the MICS methodology is reported elsewhere $[9,10]$. However, in brief, the sample was drawn using a 3-stage stratified sampling method. During the first stage of sampling, mahallas (villages) were selected with probability proportional to population size in each sub-district (Qada'a). In the second stage, mahallas were divided into compartments with population of about 500 people, and one or more compartments were then selected from each mahalla. Further, each compartment was divided into Majals (blocks) of 25-30 households in urban area and 20-25 households in rural areas. One Majal was then selected by simple random sampling from each compartment. Finally, a cluster of 10 households was selected from each Majal using a systematic random sampling technique. All18 governorates of the country were represented in the sample.

\section{Questionnaire administration}

A standardized MICS questionnaire provided by UNICEF was translated into Arabic by the Middle East and North Africa Regional Office of UNICEF (MENARO), with some revisions and adaptations. The revised questionnaire was pretested in August 2000.

Of the 13,220 women who had delivered a child 13,114 $(99.2 \%)$ were eventually interviewed as women who had delivered a child within the last 12 month.

\section{Ethical consideration}

The Iraqi MICS survey of 2000 was conducted by the government with technical support from UNICEF. We obtained de-identified data from UNICEF which we analysed within the current secondary study. Our analysis of de-identified secondary data was exempted from full institutional review board.

\section{Data analysis}

We conducted weighted analysis using SPSS version 11.5 (Statistical Package for Social Sciences, Chicago, Illinois, United States). We obtained frequencies and proportions to describe the sample with regard to the outcome of interest (i.e. having been supervised by a TBA in delivery occurring within the last 12 months) and other sociodemographic characteristics.

The outcome variable was categorized into being assisted during delivery by TBAs and being assisted by health professional (doctor, nurse/midwife, and auxiliary midwife) or relative/friend. Marital status was categorized as: cur- 
rently married/in union and not currently married. The not currently married included women who were widowed, divorced, separated or had never been married. Age was taken as completed years at the time of the survey. Wealth was measured by using household assets (such as radio, bicycle, car, television, type of roofing, and floor) rather than income as has been done in other community surveys such as the Demographic and Health Survey [1113]. Each asset was assigned a weighting value, using principal component analysis as described by the World Bank and ORC Macro. A household was assigned a standardized score for each owned asset, and these scores were summed and households ranked into five wealth quintiles.

We conducted bivariate and multivariate logistic regression methods to assess associations between predictor variables and the outcome. The unadjusted odds ratio (OR), and adjusted odds ratio (AOR) together with their 95\% confidence intervals (CI) are reported. For the purpose of our study, traditional birth attendants were not considered skilled or professional birth attendants.

\section{Results}

Altogether 22,980 women participated in the survey, and of these women, 2873 had delivery information and whether they were assisted by traditional birth attendants (TBAs) or not during delivery. About half of the women were of age 25-34 years (49.1\%), and almost all of them were married $(99.3 \%)$. The majority of the respondents had not gone further than primary level of education $(74.1 \%)$. Most of the respondents resided in urban areas $(62.8 \%)$. About 1 in 5 women (26.9\%) were assisted during delivery by TBAs. Further description of the sample with regard to key socio-demographic variables is shown in Table 1.

Table 2 shows factors associated with traditional birth attendant assisted-delivery that were considered in the analysis. Only age and marital status were not significantly associated with TBA assisted-delivery at bivariate analyses. At multivariate analysis, marital status and area of residence were not significantly associated with TBA assistance during delivery. Compared to women of age 35 years or more, women of age 25-34 years were 22\% (AOR $=1.22,95 \%$ CI $[1.08,1.39])$ more likely be assisted by TBAs during delivery. Women who had no formal education were $42 \%(\mathrm{AOR}=1.42,95 \% \mathrm{CI}[1.22,1.65])$ more likely to be delivered by TBAs compared to those who had attained secondary or higher level of education. Women in the poorest and middle wealth quintiles were 2.53 $(\mathrm{AOR}=2.52,95 \% \mathrm{CI}[2.14,2.98])$ more likely, and $25 \%$ $(\mathrm{AOR}=0.75,95 \% \mathrm{CI}[0.62,0.92])$ less likely, respectively, to be delivered by TBAs compared to those in the richest
Table I: Socio-demographic description of on women who delivered within the last 12 months in the Iraq MICS of 2000

\begin{tabular}{ll}
\hline Factor & Total \\
$\mathrm{n}(\%)$
\end{tabular}

Note: numbers are not adding up because of non responses to some variables

quintile. Compared to women who had 7 or more children, those who had 1 or 2 were $28 \%$ (AOR $=0.72,95 \% \mathrm{CI}$ $[0.59,0.87])$ less likely to be delivered by TBAs.

\section{Discussion}

In a study of Iraq women in which data on delivery supervision at the most recent delivery was available for 2,873 women, $26.9 \%$ reported that they had been delivered by TBAs. In multivariable analysis we found that younger women in the age group 25 to 34 years were $22 \%$ more likely to report having been delivered by TBAs compared to women 35 years and older. We also found that higher parity, middle-income category, low education and rural residence were positively associated with delivery by traditional birth attendant. 
Table 2: Unadjusted odds ratios (OR) and adjusted odds ratios (AOR) and $95 \%$ confidence interval $(\mathrm{Cl})$ of the association of socio-demographic variables and delivery assisted by traditional birth attendant in Iraq, 2000

\begin{tabular}{|c|c|c|}
\hline Characteristics & OR $(95 \% \mathrm{Cl})$ & AOR $(95 \% \mathrm{Cl})$ \\
\hline \multicolumn{3}{|l|}{ Age (years) } \\
\hline$<25$ & $0.83(0.64,1.06)$ & $1.03(0.86,1.24)$ \\
\hline $25-34$ & $1.19(0.95,1.49)$ & $1.22(1.08,1.39)$ \\
\hline $35+$ & 1 & 1 \\
\hline \multicolumn{3}{|l|}{ Currently married } \\
\hline Yes & $0.73(0.46,1.17)$ & - \\
\hline No & 1 & \\
\hline \multicolumn{3}{|c|}{ Maternal education level } \\
\hline None & $1.86(1.64,2.12)$ & $1.42(1.22,1.65)$ \\
\hline Primary & $1.08(0.96,1.22)$ & $1.05(0.92,1.20)$ \\
\hline Secondary or higher & 1 & $\mathrm{I}$ \\
\hline \multicolumn{3}{|l|}{ Area of residence } \\
\hline Urban & $0.66(0.60,0.72)$ & - \\
\hline Rural & 1 & \\
\hline \multicolumn{3}{|c|}{ Wealth index (Quintiles) } \\
\hline Poorest & $2.90(2.49,3.39)$ & $2.52(2.14,2.98)$ \\
\hline Second & $1.27(1.06,1.52)$ & $1.14(0.95,1.37)$ \\
\hline Middle & $0.74(0.61,0.89)$ & $0.75(0.62,0.92)$ \\
\hline Fourth & $0.79(0.65,0.96)$ & $0.85(0.69,1.03)$ \\
\hline Richest & 1 & 1 \\
\hline \multicolumn{3}{|c|}{ Number of children ever born } \\
\hline I or 2 & $0.66(0.57,0.76)$ & $0.72(0.59,0.87)$ \\
\hline 3 or 4 & $1.01(0.88,1.16)$ & $1.04(0.89,1.21)$ \\
\hline 5 or 6 & $1.11(0.95,1.30)$ & $1.07(0.90,1.28)$ \\
\hline 7 or more & 1 & $\mathrm{I}$ \\
\hline
\end{tabular}

The finding that women in the middle wealth category were less likely to be delivered by TBAs compared to women in the richest category may be a spurious finding because the odds of being delivered by TBAs were not significantly different between women in the second and fourth categories on one hand and women in the richest category on the other. Women in the lowest wealth quintile were more likely to deliver under TBA supervision than women in the richest wealth category. This finding is similar to what has been published elsewhere where data have shown that women in poor households are less likely to receive professional medical care $[14,15]$.

Access to health care facilities may be limited as a result of transport and hospital fees [16]. Lawoyin [17] has reported high neonatal adverse outcomes among deliveries occurring out of health care facilities. While facility deliveries are preferred wherever possible, Leigh et al [18] have reported on poor maternal outcomes in Malawi within health facilities, largely because of low quality of care. Furthermore, supervised midwifery deliveries at home must be differentiated from low-skilled traditional birth attendant supervision. Just because a delivery occurs at home should not necessarily imply it is of low quality. In an environment where transport and communication facilities are available, delay can be minimised, safe home deliveries can be provided, while expecting that transfer to a facility with capabilities to provide higher level care is possible $[19,20]$.

We also found that parity i.e. the number of children a woman has ever delivered was associated with TBA supervisions. Women who may have previous non-eventful deliveries may be complacent and expect that TBA assisted deliveries are safe. Primiparas may have been less likely to be delivered by TBAs because they may not have been sure of their pregnancy outcome, and would have liked to be attended by professional skilled persons during delivery.

Women with low education were more likely to be delivered under the supervision of TBAs. The higher likelihood of TBA deliveries by low education women may also be associated with limited appreciation by women with limited education to understand the need for professional supervision during delivery. Our findings is similar to that reported by Tann et al [21] that skilled birth attendants remain difficult to be accessed by less educated women.

While this study has obvious strength such as the design being tailored to produce nationally representative data and use of a standard MICS questionnaire, there are a number of limitations worth considering. In comparing these results with similar studies in which rural versus urban residence status was assessed, it is important to remember that the definitions of urban versus rural may differ from country to country [22-24]. In the Iraq MICS, an urban area was defined as any administrative setup lying within the municipality boards; areas other than these were considered rural. Furthermore, data were collected via self-reports.

To the extent that study participants intentionally or inadvertently misreported, our findings may be biased. Finally, although the data collected were cross sectional in nature, and we are not able to ascertain causation between any of the variables and the outcome [25] i.e. having been delivered by a traditional birth attendant, the current findings are consistent with those of the previous studies. These factors should be considered in designing interventions to reduce the rate of TBA assisted deliveries, and hence reduce neonatal and maternal mortality rates, rather than generating hypotheses and considering similar future research using study designs that are higher than cross sectional studies. Missing information in the Iraq 2000 MICS data is of concern, and our findings may be biased to the extent that non-respondents differed from 
those that responded to the questionnaire items we considered in our analysis.

\section{Conclusion}

Findings from this study indicate that having delivery supervised by traditional birth attendants was associated with young adult age, low education, and being poor. Meanwhile, women having 1 or 2 children were less likely to be delivered by TBAs. These factors should be considered in the design of interventions aimed to promote professional delivery with the consequent aim of reducing the proportion of deliveries assisted by TBAs. This may result in the reduction of maternal and neonatal mortality rates.

\section{Competing interests}

The authors declare that they have no competing interests.

\section{Authors' contributions}

SS conducted the data analysis, participated in the interpretations of the results and drafting of the manuscript. ASM participated in the interpretations of the results and drafting of the manuscript. ER participated in the interpretations of the results and drafting of the manuscript. All authors read and approved the final manuscript.

\section{Acknowledgements}

We thank the United Nations Children's Fund (UNICEF) for making these data available to us for analysis. This study would not have been possible without the participation of the women in Iraq.

\section{References}

I. Rasch V: Maternal death and the Millennium Development Goals. Dan Med Bull 2007, 54:167-9.

2. Countdown Coverage Writing Group; Countdown to 2015 Core Group, Bryce J, Daelmans B, Dwivedi A, Fauveau V, Lawn JE, Mason E, Newby H, Shankar A, Starrs A, Wardlaw T: Countdown to 2015 for maternal, newborn, and child survival: the 2008 report on tracking coverage of interventions. Lancet 2008, 37 I: | 247-58.

3. Mpembeni RN, Killewo JZ, Leshabari MT, Massawe SN, Jahn A, Mushi $D$, Mwakipa $H$ : Use pattern of maternal health services and determinants of skilled care during delivery in Southern Tanzania: implications for achievement of MDG-5 targets. BMC Pregnancy Childbirth 2007, 7:29.

4. Darmstadt GL, Hussein MH, Winch PJ, Haws RA, Gipson R, Santosham M: Practices of rural Egyptian birth attendants during the antenatal, intrapartum and early neonatal periods. J Health Popul Nutr 2008, 26:36-45.

5. Anwar I, Sami M, Akhtar N, Chowdhury ME, Salma U, Rahman M, Koblinsky M: Inequity in maternal health-care services: evidence from home-based skilled-birth-attendant programmes in Bangladesh. Bull World Health Organ 2008, 86:252-9.

6. Fronczak N, Arifeen SE, Moran AC, Caulfield LE, Baqui AH: Delivery practices of traditional birth attendants in Dhaka slums, Bangladesh. J Health Popul Nutr 2007, 25:479-87.

7. Maternal, Child and Reproductive Health Strategy in Iraq 2005-2008 Ministry of Health, Iraq 2008 [http://www.emro.who.int/ iraq/pdf/Maternal ChildHealth.pdf].

8. UNICEF (United Nations International Children's Education Fund): Report on the consultation on attendance at birth: community birth attendants Health Section, Programme Division, United Nations Children's Fund/New York; 1997.

9. United Nations Children's Fund (UNICEF): Multiple Indicator Cluster Survey (MICS), Tajikistan Dushanbe: UNICEF; 2000.
10. Republic of Iraq and United Nations Children Fund: Multiple Indicator Cluster Survey for the year 2000 (Detailed report). Baghdad 200I [http:// www.childinfo.org/files/iraql.pdf].

II. Filmer D, Pritchett L: Estimating wealth effects without expenditure data or tears: an application to educational enrolments in states of India. Demography 200I, 38: I I5-32.

12. Sahn DE, Stifel DC: Poverty comparisons over time and across countries in Africa. World Development 2000, 28:2/23-55.

13. Rutstein SO, Johnson K: The DHS Wealth Index. DHS Comparative Reports No. 62004 [http://www.nso.malawi.net/data on line/demog raphy/mics/MICS\%20Report.pdf]. Calverton, Maryland: ORC Macro

14. Kruk ME, Prescott MR, Galea S: Equity of skilled birth attendant utilization in developing countries: financing and policy determinants. Am J Public Health 2008, 98: 142-7.

15. Koblinsky M, Matthews Z, Hussein J, Mavalankar D, Mridha MK, Anwar I, Achadi E, Adjei S, Padmanabhan P, Marchal B, De Brouwere $\checkmark$, van Lerberghe W, Lancet Maternal Survival Series steering group: Going to scale with professional skilled care. Lancet 2006, 368: $1377-86$.

16. Tlebere $P$, Jackson D, Loveday M, Matizirofa L, Mbombo N, Doherty T, Wigton A, Treger L, Chopra M: Community-based situation analysis of maternal and neonatal care in South Africa to explore factors that impact utilization of maternal health services. J Midwifery Womens Health 2007, 52:342-50.

17. Lawoyin TO: Infant and maternal deaths in rural south west Nigeria: a prospective study. Afr J Med Med Sci 2007, 36:235-4I.

18. Leigh B, Mwale TG, Lazaro D, Lunguzi J: Emergency obstetric care: how do we stand in Malawi? Int J Gynaecol Obstet 2008, I0I:I07-II.

19. Leslie MS, Romano A: Appendix: Birth can safely take place at home and in birthing centers: The coalition for improving maternity services. J Perinat Educ 2007, I 6(SuppI I):8IS-88S.

20. Lindgren HE, Hildingsson IM, Christensson K, Rådestad IJ: Transfers in planned home births related to midwife availability and continuity: a nationwide population-based study. Birth 2008, 35:9-15.

21. Tann CJ, Kizza M, Morison L, Mabey D, Muwanga M, Grosskurth H, Elliot AM: Use of antenatal services and delivery care in Entebbe, Uganda: a community survey. BMC Pregnancy Childbirth 2007, 7:23.

22. Muula A: How do we define 'rurality' in the teaching on medical demography? Rural Remote Health 2007, 7:653.

23. Rourke J: In search of a definition of 'rural'. Can J Rural Med 1997, 2:113-II5.

24. Roos N, Fransoo R, Bogdanovic B, Friesen D, Frohlich N, Carriere KC: Needs-based planning for Manitoba's generalist physicians Winnipeg: Manitoba Centre for Health Policy and Evaluation, University of Manitoba; 1996.

25. Kaufman JS, Kaufman S: Estimating causal effects. Int J Epidemiol 2002, 31:43I-2.

\section{Pre-publication history}

The pre-publication history for this paper can be accessed here:

http://www.biomedcentral.com/1472-698X/9/7/prepub

Publish with Biomed Central and every
scientist can read your work free of charge
"BioMed Central will be the most significant development for
disseminating the results of biomedical research in our lifetime. "
Sir Paul Nurse, Cancer Research UK
Your research papers will be:
• available free of charge to the entire biomedical community
• peer reviewed and published immediately upon acceptance
• cited in PubMed and archived on PubMed Central
• yours - you keep the copyright
Submit your manuscript here:
http://www.biomedcentral.com/info/publishing_adv.asp

